\title{
SUB-CLINICAL RHEUMATIC CARDITIS
}

\author{
BY \\ R. LANNIGAN \\ From the Department of Pathology, University of Birmingham
}

Received June 1, 1959

Since the operation of mitral valvotomy was introduced, various attempts have been made to explain the high incidence of histologically active lesions in biopsies of the left atrial appendages removed at operation, in view of the low incidence of active lesions found at necropsy in clinically inactive cases of rheumatic heart disease. Several clinico-pathological studies have been made in biopsy series (Kuschner et al., 1952; Catto et al., 1952; Biörck et al., 1952; Sabiston and Follis, 1952; McNeely et al., 1953; Manchester et al., 1955; Clark and Anderson, 1955; Elster and Wood, 1955), but no correlation has been found between the presence of histologically active lesions and the usual clinical and laboratory criteria of rheumatic activity.

Most of the figures on the incidence of active lesions in left atrial appendages in biopsy series refer to the presence of Aschoff nodules, although there are considerable differences in what are interpreted as Aschoff nodules. Little attention has been paid to mucoid changes and cellular infiltrations in the subendocardium, which also appear to be part of the rheumatic process. The histological criteria used for rheumatic activity in this series have been described elsewhere (Lannigan, 1959).

The following is a description of a clinico-pathological correlation in a series of 175 patients who had mitral valvotomy and a necropsy series of 61 cases of rheumatic heart disease.

\section{MeTHODS AND MATERIALS}

The first 175 cases of mitral valvotomy at the United Birmingham Hospitals were analysed. The left atrial appendage removed at operation was examined hitologically in every case. From the notes the following information was obtained: age, sex, history of rheumatic fever or chorea with dates of first and subsequent attacks, if any, duration of symptoms, dyspnœa, hæmoptysis, attacks of congestive cardiac failure at the time of operation or at any time previously, involvement of valves in addition to mitral disease, hæmoglobin, E.S.R., W.B.C., administration of drugs, presence of calcification, and stenosis or regurgitation at operation.

For comparison with the biopsies, a series of 61 consecutive cases was collected from necropsies in the U.B.H., in which there was macroscopic evidence of rheumatic heart disease. This was the only selection factor adopted initially and the patients were from all age groups. The hearts were fixed whole and 20 blocks of tissue were examined from each specimen. From this original series the following cases were rejected.

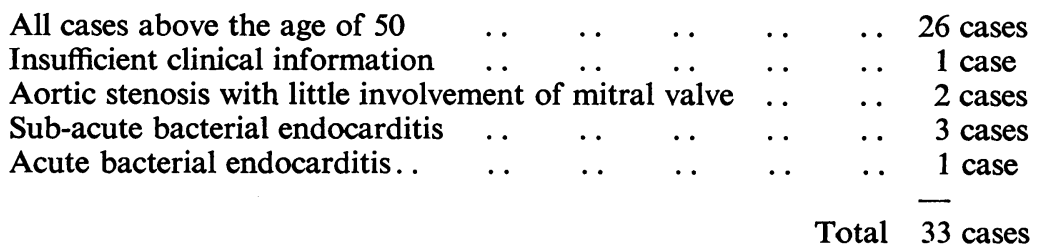


Twenty-eight cases were left in the series under the age of 50 and all had mitral valve disease. Fourteen of these had involvement of the aortic valve also. The selection of cases apart from age was made on a pathological basis and no further clinical sub-division was made for the following reasons.

(1) The majority of these patients (26 of the 28) died in congestive cardiac failure, while a relatively small proportion (34 of 175) in the valvotomy series were in congestive failure prior to operation.

(2) Many of these patients were admitted in severe congestive failure and died shortly after admission, often before complete investigations could be made. This necropsy series may therefore include cases of acute or sub-acute rheumatic fever and three cases were believed to have a recrudescence of active disease in their final illness. None had subcutaneous nodules or skin rashes.

Of the 61 cases in the whole necropsy series, $12(20 \%)$ showed active lesions in the heart and of these $10(17 \%)$ had lesions in the left atrial appendage. Of the 28 cases used for comparison with the biopsy series, $7(25 \%)$ had active lesions in the heart and $5(18 \%)$ of these had lesions in the left atrial appendage. This compares with 112 of $175(64 \%)$ in the biopsy series.

The histological examinations in the biopsy and necropsy series were carried out without reference to any clinical data. The information was transferred to punch cards and analysed.

\section{RESULTS}

Biopsy Series. In all except one patient the temperature range was within normal limits and the pulse rates in those not receiving digitalis were also in the normal range. Apart from a few women with an iron deficiency anæmia, the hæmoglobin values were also within normal limits.

None of these patients showed clinical evidence of acute or sub-acute rheumatism, although in a few there were grounds for suspecting this, e.g. a persistently raised E.S.R., a pulse rate remaining at the top range of normal, or perhaps a fairly rapid development of congestive cardiac failure. Rheumatic nodules, joint pains, and skin manifestations were absent in all cases.

Patients with histologically active rheumatism will be denoted "postitive" (+) and the remainder "negative" (-). A separate analysis of men and women rarely showed any sex difference.

There were 106 women and 69 men. The age distribution is given in Fig. 1, the range being 12-53 years. All except 25 were between the ages of 25 and 49 years: 64.2 per cent of the female and 63.8 per cent of the male patients were positive. Ninety-four $(53 \%)$ gave a history of rheumatic fever or chorea. Sixy per cent of women and 43 per cent of men gave a rheumatic history, a sex difference which is significant $\left(\chi^{2}=5.5 ; p<0.02\right)$. Fifty-five per cent of "positive" cases and 51 per cent of "negative" cases gave a history of rheumatic fever. The age distribution with respect to the presence of active lesions is shown in Fig. 2. In all age groups below 50, the number of positives exceeds the negatives. Up to age group 35-39 years there is an increasing proportion of negatives, but above this the proportions remain fairly constant.

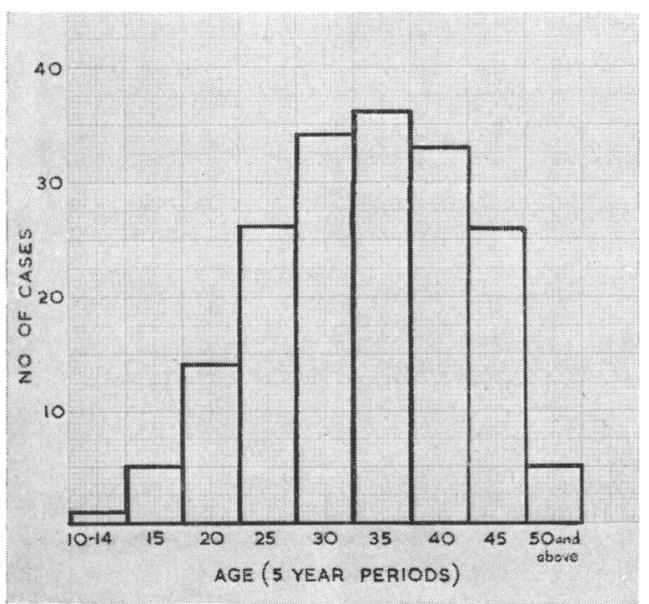

Fig. 1.-Biopsy series. Age distribution. (175 cases.)

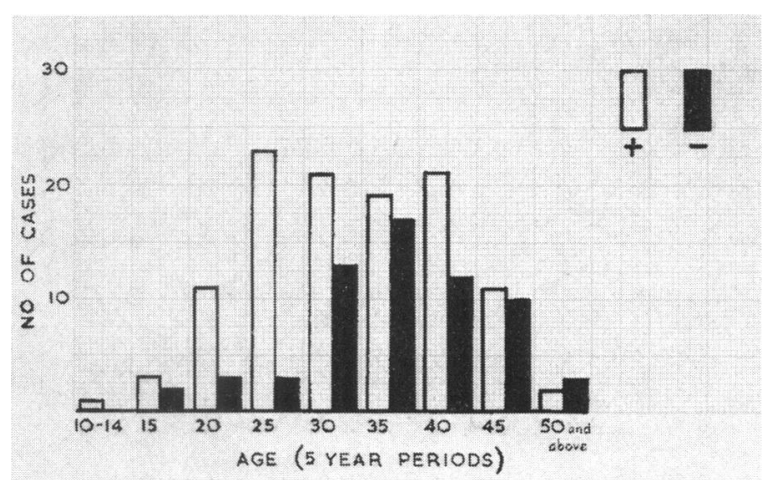

FIG. 2.-Biopsy series. The relation of age to the presence of active lesions. 
Table $I$ is an analysis of some of the clinical data. In each case the analysis is with respect to the total incidence of active lesions. E.S.R. rates (Wintrobe corrected readings) of over $10 \mathrm{~mm}$. in one hour for men and $20 \mathrm{~mm}$. for women were accepted as abnormal. These are higher levels than usual and were adopted in an attempt to limit the effect of other factors.

TABLE I

Biopsy Series. Clinical Data in Relation to the Presence $(+)$ or Absence (-) of Active Lesions

\begin{tabular}{|c|c|c|c|c|c|c|}
\hline \multicolumn{4}{|c|}{ Clinical findings } & No. of cases & + & - \\
\hline \multirow{2}{*}{\multicolumn{4}{|c|}{ 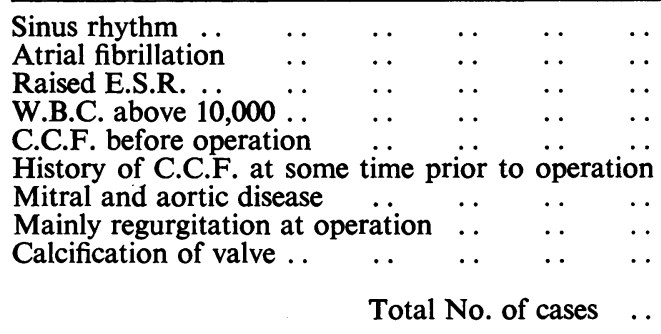 }} & $\begin{array}{l}97 \\
78 \\
23 \\
14 \\
34 \\
17 \\
32 \\
27 \\
50\end{array}$ & $\begin{array}{r}86 \\
26 \\
12 \\
9 \\
20 \\
9 \\
20 \\
16 \\
31\end{array}$ & $\begin{array}{c}11 * \\
52^{*} \\
11 \\
5 \\
14 \\
8 \\
12 \\
11 \\
19\end{array}$ \\
\hline & & & & 175 & 112 & 63 \\
\hline
\end{tabular}

* For sinus rhythm and atrial fibrillation $x^{2}=57 ; p<0.001$

For other clinical findings no conventional level of statistical significance was found.

The outstanding feature is the difference in the incidence of active lesions in patients in sinus rhythm $(89 \%+)$ and atrial fibrillation $(33 \%+)$.

Necropsy Series. Clinical information was not as complete in the necropsy series as in the biopsy series. There were 15 women and 13 men. Fig. 3 shows the age distribution of the series.

Twenty-two of the 28 gave a history of rheumatic fever or chorea. An analysis of some clinical and pathological findings with respect to the presence or absence of active lesions in the heart is shown in Table II. Comparison in this case has been made with the presence of active lesions anywhere in the heart and not with the left atrial appendage as in the biopsy series. There was no significant difference between patients in sinus rhythm and atrial fibrillation but the number of cases in sinus rhythm was small. If all cases below the age of 50 are considered, then of 35 cases in this category 6 of 10 in sinus rhythm and 4 of 25 in atrial fibrillation were positive, a significant difference $\left(\chi^{2}=6.8 ; p<0.01\right)$. A similar difference is found if all necropsy cases are considered. Thus in 59 of the 61 necropsy cases where the cardiac rhythm was known, 6 of 12 in sinus rhythm and 6 of 47 in atrial fibrillation were positive $\left(\chi^{2}=8 \cdot 2 ; p<0 \cdot 01\right)$.

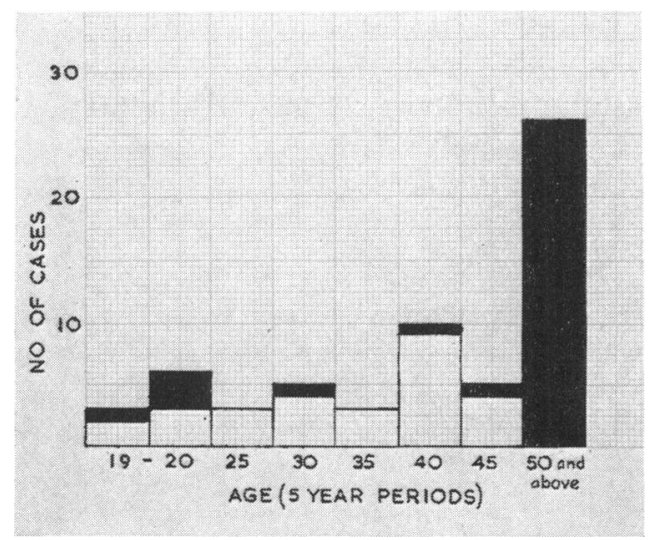

FIG. 3.-Necropsy series. Age distribution of whole series (61 cases). The shaded areas indicate the rejected cases.

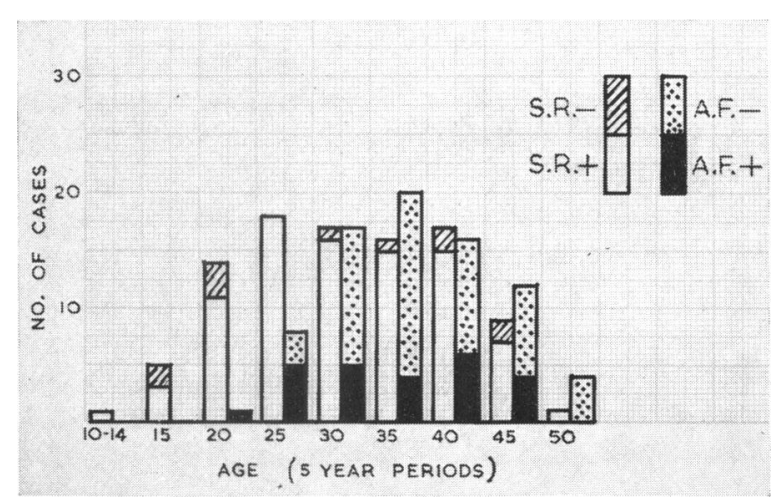

Fig. 4.-Biopsy series. Age distribution with respect to the presence of active lesions and cardiac rhythm. + and - as defined on p. 36. 
TABLE II

Necropsy Series. Clinical Data in Relation to the Presence (+) or Absence (-) of Active lesions

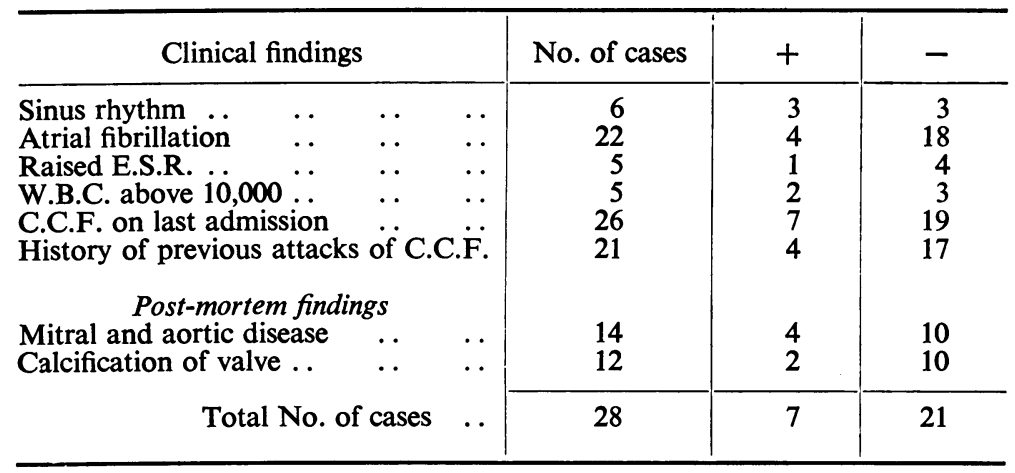

\section{Rheumatic Activity and Cardiac Rhythm}

The difference in incidence of active lesions in sinus rhythm and atrial fibrillation was investigated further. This was done only in the biopsy series since the numbers were small in the necropsy series. The following factors were considered.

(a) The possibility of some factor in the left atrial appendage in patients with atrial fibrillation that would obscure active histological lesions. The most obvious difference is the presence of organizing or organized thrombus which was noted in 46 cases in atrial fibrillation and 4 in sinus rhythm. Of the 46 cases in fibrillation, 11 showed active lesions and 3 of the 4 in sinus rhythm were also positive. As described elsewhere (Lannigan, 1959), the subendocardium is frequently not involved in the organizing process, although the endocardium itself may show an inflammatory reaction. In those cases in which Aschoff nodules were found in specimens together with organizing thrombus, there was no special relation between thrombus formation and the situation of the rheumatic lesions. For these reasons it is not considered that organizing thrombus is obscuring the tissue reaction in many cases.

(b) The age of the patients. The age distribution with respect to cardiac rhythm and the presence of active histological lesions is shown in Fig. 4. The proportion of patients with atrial fibrillation rises until age group 35-39 and remains fairly constant in the older age groups. In patients in sinus rhythm the number of positives greatly exceeds the negatives at all ages. When patients with atrial fibrillation are considered, the proportion of positives decreases until age group 35-39, but in the fifth decade the decrease is not continued. From the graph it can be seen that age by itself does not account for the difference in incidence of active lesions between patients in sinus rhythm and atrial fibrillation.

(c) Time interval between last attack of rheumatic fever and date of operation. This was given in 75 patients. It varied from 2-40 years and no correlation was found with the presence of active lesions.

(d) Length of history of the disease. The total duration of rheumatic disease was not known but the date of the first acute attack of rheumatic fever was used to compare the incidence of active lesions with the length of history of the disease. This was known for 72 patients, 36 of whom were in sinus rhythm. Fig. 5 shows the relation of the duration of illness to the presence of active lesions and cardiac rhythm. Up to 14 years from the first acute attack all except one case had active lesions. Beyond this the proportions were variable. Up to 14 years all were in sinus rhythm. Beyond this the proportion in fibrillation increased and from 20 years exceeded that in sinus rhythm. Although the bulk of patients in sinus rhythm gave a shorter history than those fibrillating, there was no evidence within the group showing atrial fibrillation that the presence of active lesions is related to the duration of the disease.

Fig. 5 does not take the age of the patients into account. A breakdown into 10-year age periods provides little additional information since the numbers in each group are too small to draw conclusions. Those with atrial fibrillation tend to have a longer history than those in sinus rhythm in each age group, and for positive cases tend to have a shorter history than negative cases except in age group 40-49 years.

(e) Drugs. Salicylates were not administered regularly to any patient. When digitalis preparations were considered, there was difficulty in getting sufficient information, as to how regularly the patient was taking these drugs before admission for operation. Of 73 cases in which specific mention was made of 


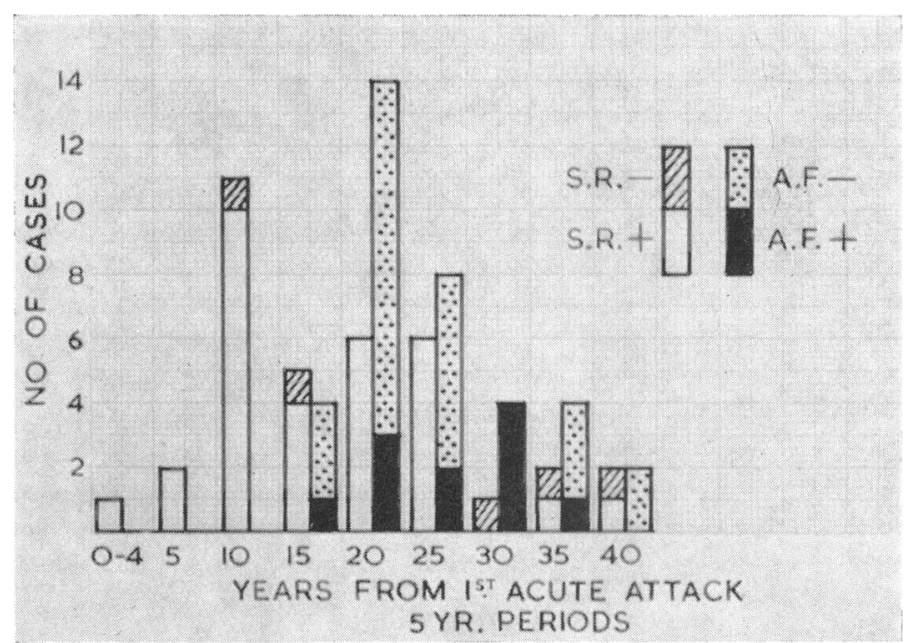

Fig. 5.-Biopsy series. The relationship of the presence of active lesions, cardiac rhythm and time interval between first acute attack of rheumatic fever and operation. (72 cases.)

digitalis preparations, 58 were taking digitalis regularly before admission for operation and 15 were not. Twenty-eight cases out of 58 taking digitalis and 13 of 15 not taking digitalis were positive, a large difference in incidence. There is, however, a difference in the proportions of patients in sinus rhythm and atrial fibrillation taking digitalis preparations. Of 26 patients with sinus rhythm, the 2 without active lesions and 12 of the 24 with active lesions were not taking digitalis. Of 47 with atrial fibrillation, all the 30 without active lesions and 16 of the 17 with active lesions were taking digitalis. If these figures are compared with the total number of cases with atrial fibrillation in the series, 16 of 26 positive cases were known to be taking digitalis and $\mathbf{3 0}$ of $\mathbf{5 0}$ negative cases were also taking digitalis. There is no evidence that digitalis has any effect on the incidence of active lesions.

\section{Discussion}

No correlation was found in the biopsy or necropsy series between the presence of histologically active lesions and the usual clinical criteria of rheumatic activity, a general finding in other biopsy series. Other laboratory methods, e.g. anti-streptolysin $\mathbf{O}$ titres and the presence of $\mathbf{C}$ reactive protein have also shown no correlation with the histological findings (Elster and Wood, 1955). Sabiston and Follis (1952) found a correlation with the E.S.R. level, but most others have not.

Most investigators think from studies on atrial appendage biopsies that the presence of histological lesions is indicative of active rheumatism, in spite of the absence of clinical evidence. Occasional dissentient views have been expressed. Enticknap (1953), for example, suggested the possibility of a different disease from rheumatic carditis, but this view has received no support from comparative necropsy studies (Thomas et al., 1953). Tedeschi et al., 1955, put forward the view that most lesions in biopsy specimens are senescent and not indicative of rheumatic activity. They do not accept the idea of sub-clinical rheumatism although they describe 8 biopsy specimens out of 400 with "acute" lesions: these 8 cases did not have clinical evidence of rheumatism apart from a raised E.S.R. They attribute this discrepancy between the histological and clinical findings to antibiotic or steroid therapy. In the present series the earliest forms of rheumatic lesions were found in some biopsy specimens and none of the patients were receiving prophylactic antibiotics or steroids. Pinniger (1951), McKeown (1953), and Thomas et al. (1953) have also described early forms of lesions in valvotomy specimens. The presence of early lesions without clinical evidence of active disease suggests that rheumatic carditis can be sub-clinical. This reinforces the views of Coombs (1924), Smith (1925), Gross and Ehrlich (1934), and others. 
Some confusion has arisen over the use of the term "active". Tedeschi et al. (1955), for example, use "active" and "acute" as synonymous. In the present series the term "active" has been used in a histological sense to indicate the presence of the rheumatic process from the earliest stages until the stage of obvious fibrosis. The division into developing and healing is arbitrary and no attempt has been made to do so in this series. It is plain that patients undergoing valvot omy do not have acute or subacute rheumatic fever, but the presence of the earliest forms of lesion in some biopsy specimens strongly suggests that rheumatic lesions can develop and retrogress without producing the usual clinical or laboratory features of rheumatic fever. The importance of sub-clinical rheumatism in relation to the natural history of the disease has thus been reinforced since valvotomy was introduced. Undue stress has perhaps been placed on the acute attack of rheumatic fever in clinical and pathological descriptions of the disease. In this series 81 patients $(47 \%)$ gave no history of rheumatic fever or chorea and 50 of these $(62 \%)$ showed evidence of rheumatic activity in the left atrial appendage.

It appears from the high incidence of histologically active lesions that "attacks" of sub-clinical rheumatism occur frequently and there is some evidence that they may overlap. In 18 biopsy specimens diagnostic active lesions at different stages of development were found in the same specimen and in 64 cases non-specific changes-mucoid œdema and cellular infiltration-were found in addition to developed lesions. These non-specific changes have been described by Talajajew (1929), Klinge (1933), and Gross and Ehrlich (1934) as preceding the development of changes in the collagen, and some of these in biopsy specimens may represent early developing lesions. Von Glahn (1926) and McKeown (1946) were also of the opinion that attacks of rheumatism are sometimes superimposed. Repeated recurrences of sub-clinical rheumatism provide a more satisfactory explanation for the progressive damage to the heart than occasional or even hypothetical attacks of acute rheumatic fever. The role played by organizing thrombus in the development of valvular deformities (Magarey, 1951; Tweedy, 1956) is outside the scope of this investigation but it appears likely that both active rheumatism and organizing thrombus are concerned in the production of sclerosis of the valve cusps.

It has to be remembered, however, that valvotomies are carried out on a selected group of patients and it is important to know if this group is representative of rheumatic carditis in general. Since the introduction of valvotomy the criteria for operation have considerably widened. The case histories show that while all patients are dyspnœic on exertion, the physical disability ranges from a moderate degree, where patients are able to walk fairly long distances without undue disturbance, to bed-ridden orthopnœic patients. The extent of the valvular damage is also very variable. Figures are not readily available in this centre as to the proportions of patients with mitral valve diseases who are submitted to valvotomy, but Fraser et al. (1955) state that 50 per cent of their cases with mitral stenosis were referred for surgery. This is a substantial proportion and probably the selection factor in patients undergoing valvotomy is not as great as one might suspect. It has been suggested that patients may be selected for valvotomy, because their symptoms have become worse and this deterioration in their condition might be the result of renewed rheumatic activity. From the histories in this series there is no evidence of any marked recent deterioration in many patients, although many have been steadily becoming worse for some years.

\section{Active Rheumatic Lesions and Cardiac Rhythm}

The difference in incidence of active lesions in patients in sinus rhythm and atrial fibrillation has been shown here in biopsy specimens and to a lesser extent in necropsy cases. Coombs (1924) first made the observation that patients who were fibrillating showed little evidence of rheumatic activity: he noted clinically active rheumatism in only 9 of 58 cases with fibrillation and only 1 in 12 necropsy cases showed active lesions. McNeely et al. (1953) in a clinico-pathological correlation of a biopsy series of 183 left atrial appendages showed a large difference in incidence of Aschoff nodules in sinus rhythm $(76 \%+)$ and in atrial fibrillation $(16 \%+)$. They adopted Aschoff nodules as their criteria and, while they mention "non-specific" lesions, these are not included in their 
analyses. The low incidence of active lesions in fibrillation has been confirmed by Manchester et al. (1955) but Sabiston and Follis (1953) did not note any difference between those in sinus rhythm and those in atrial fibrillation.

The explanation for the low incidence of active lesions in atrial fibrillation has not been found. It appears from this series that patients who are fibrillating have had their disease for longer periods than those in sinus rhythm. It is possible that the conditions necessary for the development of fibrillation are associated more with the healed process than with the active disease process. It is also possible that the disease is becoming quiescent as fibrillation develops or that recurrences of sub-clinical rheumatism are occurring at less frequent intervals.

The difference in proportions of patients in sinus rhythm and atrial fibrillation in biopsy and necropsy series may account in part for the low incidence of active lesions in most necropsy series of cases of mitral valve disease. In the present series the ratio of patients in sinus rhythm, to those in atrial fibrillation was $1: 0.8$ in the biopsy, and $1: 3.6$ in the necropsy series. This is not, however, likely to be the whole explanation since the incidence of active lesions in sinus rhythm in the necropsy series was lower than in the biopsy series.

It is of course obvious that no necropsy series is really comparable with the biopsy series. A group of patients with mitral valve disease and similar age distribution dying accidentally or from some disease unassociated with their cardiac condition would be difficult to find. In the present necropsy series used as comparison, the largest age group is in the fifth decade as compared with the fourth decade in the biopsy series. Other differences are found in the proportion of patients with multiple valve lesions and with congestive cardiac failure. Comparison between the two series must therefore be limited in scope.

\section{Comparison with Other Biopsy Series}

The reported incidence of active lesions in left atrial appendages from valvotomy operations shows a considerable variation from centre to centre (Pinniger (1951) 67 per cent; Waaler (1952) 25 per cent; Decker et al. (1953), 46 per cent; McKeown (1953) 45 per cent; Gil et al. (1955) 75 per cent). In most cases the incidence is of "Aschoff nodules" but there are differences in the histological criteria. It is possible, however, that some of the variation is due to the types of patient selected for operation. Most series do not give sufficient clinical information but in some there are sufficient data to compare with the present series.

In the 183 cases reported by McNeely et al. (1953), 46 per cent showed Aschoff nodules. The proportion of patients in sinus rhythm was 47 per cent as compared with 56 per cent in this series. They showed a decrease in incidence of Aschoff nodules with age, but from their table it can be seen that there was a steady rise in the proportion of patients in atrial fibrillation which amounted to 75 per cent of patients in the fifth decade. In the present series the proportions of patients in fibrillation rose until age group 35-39 but remained constant after this. Fifty-two per cent in this series were fibrillating in the fifth decade. From their graph it can be seen that the decrease in incidence with age is largely the result of the increasing proportion of patients with fibrillation. There is some decrease with age in the incidence of Aschoff nodules in patients who are in sinus rhythm, but this still amounts to 58 per cent in the fifth decade. Other differences are noted in the age distribution of the patients. In McNeely's series, there were fewer patients below and more above as compared with the present series. There are also differences in the numbers with additional aortic valve disease (their series 76; this series 32 ) and with organizing thrombus (their series 71 ; this series 50). It appears that the type of patient submitted to valvotomy makes a considerable difference in the total incidence of active lesions found.

If the view that rheumatic carditis is frequently sub-clinical is accepted, then doubt must be cast on the value of the measures recommended for prophylaxis in the recent report of the Rheumatic Fever Committee of the Royal College of Physicians (1957). It would appear from the results obtained in the present series and many other published series on valvotomy specimens that any 
suppressive or prophylactic measures should be continued throughout the life of the patient. It is insufficient to base the results of therapy or prophylaxis on clinical recurrences of rheumatic fever.

\section{SUMMARY AND CONCLUSIONS}

In a series of 175 biopsy specimens of left atrial appendages from mitral valvotomy operations, active histological lesions were found in $112(64 \%)$. In a necropsy series of comparable age and comparable valve lesions the total incidence of active lesions in the heart was 24 per cent.

No correlation was found between the usual clinical criteria of rheumatic activity and the presence of histologically active lesions. Since the earliest forms of rheumatic lesions were found in some specimens in the absence of clinical evidence of rheumatic activity, it is deduced that rheumatic carditis can be sub-clinical.

A large difference in the incidence of active lesions was found in patients in sinus rhythm and in atrial fibrillation in the biopsy series and to a lesser extent in the necropsy series. It is suggested that the different proportions of patients in sinus rhythm in biopsy and necropsy series may account in part for the difference in incidence of active lesions in most biopsy and necropsy series. The explanation for the low incidence of active lesions in atrial fibrillation has not been found, but it is suggested that the conditions leading to the development of atrial fibrillation are associated with the healed rheumatic process.

In view of the frequent occurrence of sub-clinical rheumatism it is suggested that prophylactic or suppressive measures should be continued throughout life.

I wish to acknowledge the willing co-operation and valuable criticism of Mr. d'Abreu, Mr. Collis and the physicians of the United Birmingham Hospitals. The Endowment Fund of the United Birmingham Hospitals provided some financial assistance.

\section{REFERENCES}

Biörck, G., Winblad, S., and Wulff, H. B. (1952). Amer. Heart J., 44, 325.

Catto, Mary, Smith, G., and Taylor, W. A. (1952). J. Path. Bact., 64, 673.

Clark, R. M., and Anderson, W. (1955). Amer. J. Path., 31, 809.

Coombs, C. F. (1924). Rheumatic Heart Disease. Bristol.

Decker, J. P., Hawn, C. van Z., and Robbins, S. L. (1953). Circulation (N. Y.), 8, 161.

Elster, S. K., and Wood, H. F. (1955). Amer. Heart J., 50, 706.

Enticknap, J. B. (1953). Brit. Heart J., 15, 37.

Fraser, H. R. L., and Turner, R. W. D. (1955). Brit. med. J., 2, 1414.

Gil, J. R., Rodriguez, H., and Ibarra, J. J. (1955). Amer. Heart J., 50, 912.

Glahn, W. C., von (1926). Amer. J. Path., 2, 1.

Gross, L., and Ehrlich, J. C. (1934). Amer. J. Path., 10, 467.

Klinge, F. (1933). Ergebn. allg. Path. path. Anat., 27, 1.

Kuschner, M., Ferrer, M. I., Harvey, R. M., and Wylie, R. H. (1952). Amer. Heart J., 43, 286.

Lannigan, R. (1959). J. Path. Bact., 77, 49.

McKeown, E. F. (1945). Ulster med. J., 14, 97.

(1953). Brit. Heart J., 15, 433.

McNeely, V. F., Ellis, L. B., and Harker, D. E. (1953). Circulation (N. Y.), 8, 337.

Magarey, F. R. (1951). Brit. med.J., 1,856.

Manchester, B., Scotti, T. M., Reynolds, M. L., and Dawson, W. H. (1955). Arch. intern. Med., $95,231$.

Pinniger, J. L. (1951). St. Thom. Hosp. Rep., 7, 54.

Sabiston, D. C., and Follis, R. H., Jr. (1952). Bull. Johns Hopk. Hosp., 91, 178.

Smith, F. M. (1925). Amer. Heart J., 1, 232.

Talajajew, W. T. (1929). Klin. Wschr., 8, 124.

Tedeschi, C. G., Wagner, B. M., and Pani, K. C. (1955). Arch. Path., 60, 408.

Thomas, W. A., Averill, J. H., Castleman, B., and Bland, E. F. (1953). New Engl. J. Med., $249,761$.

Tweedy, P. S. (1956). Brit. Heart J., 18, 175.

Waaler, E. (1952). Acta path. microbiol. scand. Suppl. 93, 211. 